\title{
Plasma HPV DNA is detectable in oral leukoplakia patients
}

\author{
Lígia Lavezo Ferreira ${ }^{\mathrm{a}, *}$, Éder Ricardo Biasoli ${ }^{a}$, Daniel Galera Bernabé ${ }^{\mathrm{a}}$, \\ Cáris Maroni Nunes ${ }^{\mathrm{b}}$, Glauco Issamu Miyahara ${ }^{\mathrm{a}}$ \\ a Oral Oncology Center and Department of Pathology and Clinical Propaedeutics, Araçatuba School of Dentistry, São Paulo State University (UNESP - Univ \\ Estadual Paulista), Araçatuba, São Paulo, 16015-050, Brazil \\ ${ }^{\mathrm{b}}$ Department of Animal Health and Production, School of Veterinary Medicine, São Paulo State University (UNESP - Univ Estadual Paulista), Araçatuba, São \\ Paulo, 16050-680, Brazil
}

\section{A R T I C L E I N F O}

\section{Article history:}

Received 21 October 2016

Received in revised form 5 March 2017

Accepted 12 April 2017

\section{Keywords:}

Leukoplakia

Plasma

Tissues

DNA

Papillomaviridae

Polymerase chain reaction

\begin{abstract}
A B S T R A C T
Background: Oral leukoplakia is considered a potentially malignant lesion for the development of squamous cell carcinoma, and various risk factors may be related to its development and malignant transformation, including the human papillomavirus (HPV). The aim of this case-control study was to detect the presence of HPV in fresh tissue, plasma and saliva samples obtained from patients with and without oral leukoplakia, and verify the correlation of the presence of DNA of HPV between different sources of materials.

Methods: In this study, 32 patients with oral leukoplakia and 24 patients selected in a case-control manner were included. DNA extraction from the samples was performed, and afterwards it was amplified by nested polymerase chain reaction (nPCR) for the detection of HPV (nPCR: MY09-MY11/GP05+-GP06+). Results: The DNA of HPV was found in $68.75 \%$ of the fresh tissue samples; in $50 \%$ of plasma, and in $62.5 \%$ of saliva samples in the group of patients with leukoplakia; in comparison with $45.8 \%, 54 \%$, and $45.8 \%$, in the fresh tissue, plasma and saliva samples, respectively, in the control group.

Conclusion: Based on the present study, there was no difference in the rate of HPV detection in patients with or without oral leukoplakia. However all sources tested in this study were considered suitable for HPV detection, especially plasma samples, which showed be an important non-invasive source of HPV detection in leukoplakia patients.
\end{abstract}

(c) 2017 Elsevier GmbH. All rights reserved.

\section{Introduction}

Leukoplakia is the most common potentially malignant lesion in the oral cavity, and may lead to the development of squamous cell carcinoma (SCC) [1]. The World Health Organization (WHO) has described it as a plaque or white stain that cannot be clinically or pathologically characterized as any other disease [2]. Scheifele and Reichart [3] showed that patients with oral leukoplakia presented 36 times more probability of developing SCC than those in the general population.

The etiology of leukoplakia is multifactorial, but it is mainly associated with oral habits, such as smoking and the habit of chewing tobacco, similarly to SCC [1]. HPV is now recognized as an important risk factor for the development of oropharyngeal

\footnotetext{
* Corresponding author at: Oral Oncology Center, Araçatuba School of Dentistry, Univ Estadual Paulista -UNESP, José Bonifácio Street, 1193, Vila Mendonça, 16015050, Araçatuba, São Paulo State, Brazil.

E-mail address: ligialavezo@hotmail.com (L.L. Ferreira).
}

cancers, and results of previous studies have demonstrated epidemiological and molecular evidence of the presence of the HPV genome in pre-malignant oral lesions in SCC tissues, especially of the subtypes of HPV-16 and -18 [1,4,5]. There are over 150 known genotypes of HPV and it is believed that at least 15 have oncogenic potential. The genotypes of HPV are classified as low risk (for example HPV 06-11-13-32), medium risk (HPV 31-33-35-51), and high risk (HPV 16-18) according to the degree of correlation with certain malignant neoplasias, with those of medium and high risk frequently being found in potentially malignant and malignant lesions of the anogenital tract, skin and upper aerodigestive tract $[2,6]$.

Tissue would be the best source for analyzing the rate of HPV infection, since it is an epitheliotropic virus, and presents its proliferation in the cells of the basal and parabasal layer of the epidermis or mucosa, establishing its infection in the more superficial layers of the epithelium [7]. For a long time it was believed that HPV could not be transmitted to various locations of the body through the blood, however, various studies have demonstrated that the DNA of HPV may be found in the blood circulation, including the 
peripheral blood mononuclear cells (PBMC), serum, plasma, umbilical cord and arterial blood [8]. Blood plasma has been shown to be an attractive medium for the detection of infection by HPV, since it is a non-invasive method, and blood is the only fluid that is in direct contact with all the organs [9], however, there are no studies that have made the association of the rate of detection of HPV in blood plasma with that of tissue obtained from patients with oral leukoplakia.

Saliva is a body fluid that has been shown to be adequate for the detection of HPV $[10,11]$, and because it is a non-invasive method for collecting material, it can easily be performed in any population. In addition to being easy to obtain saliva, it presents cells of different regions of the oral mucosa, thus facilitating the analysis when seeking HPV, since it is known that HPV presents predilection for certain areas of the oral cavity, such as the oropharyngeal region and tonsillar pillar [11]. When analyzing saliva samples from patients with oral SCC, SahebJamee et al. [12] found the presence of HPV in 40.9\% of the patients and in 25\% of the controls. Sayyah-Melli et al. [13] evaluated the saliva of women with genital lesions associated with HPV and detected HPV in $64.4 \%$ of the saliva samples.

In the literature there is a notable discrepancy in the results of studies conducted in oral lesions investigating infection by HPV, with a variance from $0 \%$ to $100 \%$ [4]. This is due to the difficulty of comparing results from one study to another, as a result of the different techniques used; type of source of material used and quality of collecting the material; availability of fresh, carefully collected cytologic samples; and in many cases, patients differing in age, pathology and specific risk factors $[4,6]$.

Further studies are necessary to elucidate the relationship of the role of HPV in potential malignant lesions, especially oral leukoplakias. Therefore, the aim of this study was to detect the presence of HPV in fresh tissue, blood and saliva samples obtained from patient with and without oral leukoplakia, by means of nested polymerase chain reaction (nPCR) and verify whether there is correlation of the positivity of HPV with the different sources of materials.

\section{Materials and methods}

This study was approved by the Research Ethics Committee of the Araçatuba School of Dentistry, (FOA)-UNESP, (Process No. FOA01034/2011) in June 06, 2011. Informed consent was obtained from all individual participants included in the study.

The patients that formed the study group and control were selected between the years 2011 and 2013. In order to form the Study Group, 32 patients were selected, with oral leukoplakia diagnosis confirmed after undergoing biopsy that was subjected to histological exam.

For the control group, 24 individuals without leukoplakia were selected. They were paired by sex and age with a difference of up to 5 years, and required oral surgery procedures (distal wedge or pre-prosthetic surgery).

Excluded from this study were persons who presented any type of auto-immune diseases (such as, for example: Addison's disease, celiac disease, dermatomyositis, lichen planus, multiple sclerosis, myasthenia gravis, pernicious anemia, rheumatoid arthritis, Sjögren's syndrome, systemic lupus erythematosus, scleroderma, vasculitis, psoriasis, Behçet's disease), who were in a gestational period, and those who had been treated for any type of malignant neoplasia. These are factors that change the patient's immunity and could interfere in the HPV infection.

\subsection{Data and material collection}

Individuals who smoked regularly during some time of their life were considered smokers, even those who had currently quit smoking. Non-smokers were considered those who had not made regular use of tobacco at any time of their life. For the classification of alcoholics and abstainers, the same criteria were used.

A term of free and informed consent was obtained from all the patients included in this study. The patients, both those in the study and control group were equally submitted to the collection of materials for the research. Before saliva collection, the patients were instructed not to consume beverages or water up to $30 \mathrm{~min}$ before the collection was made. To obtain saliva samples, the patients were asked to spit saliva into a $15 \mathrm{ml}$ (milliliter) falcon tube for $10 \mathrm{~min}$, in order to obtain a minimum of $5 \mathrm{ml}$ of saliva. In addition $10 \mathrm{ml}$ of blood were collected from each patient, which were deposited in tubes containing $10 \%$ tripotassium EDTA. The samples were immediately centrifuged at $1500 \mathrm{rpm}$ for $20 \mathrm{~min}$ at $4{ }^{\circ} \mathrm{C}$, to obtain the plasma.

Biopsies were performed for the purpose of diagnosis and treatment, and the samples obtained were divided into two parts: one part was conserved in formol in order to perform the routine histopathological exam and the other part was conserved in liquid nitrogen for later biomolecular exams for the detection of DNA of HPV. After obtaining the histopathological exam results, the patients with leukoplakia were divided according to the degree of dysplasia of the epithelium into: absence of dysplasia, mild, moderate and severe dysplasia. The surgical procedures (distal wedge or pre-prosthetic surgery) in control patients were performed irrespective of the research, as they were considered treatment.

All the samples were identified and stored in a freezer at $-80^{\circ} \mathrm{C}$ immediately after collection, for later submission to laboratory procedures.

\subsection{DNA extraction}

DNA was extracted from the samples in accordance with the instructions of the DNA QIAamp ${ }^{\circledR}$ mini extraction kit manufacturer (QIAGEN Ltd., Crawley, UK). The DNA obtained from all the samples was submitted to spectrophotometry (NanoDrop ${ }^{\circledR}$ ND-1000 UV-Vis) that confirmed the presence of a good quality DNA in all the samples. Subsequently, all samples were standardized and diluted in the same concentration of DNA before the PCR step.

\subsection{PCR for control human gene}

The presence and integrity of the DNA of all the samples were tested by means of amplification of the human $\beta$-globin gene, using the oligonucleotides PCO3-PCO4 which amplifies 110 base pair (bp) product [14]. As positive control for the $\beta$-globin gene, a previously tested blood sample was used and as negative control, DNA was replaced by ultrapure water. The presence of human DNA was analyzed by means of electrophoresis on $2 \%$ agarose gel in a $1 \times$ TBE buffer (Horizontal electrophoresis - Amersham Pharmacia Biotech model EP3501, Sweden) (Fig. 1). For all the samples the presence and integrity of the genomic DNA was confirmed, and afterwards they were submitted to research of the HPV gene by means of PCR in two stages (nPCR) with the primers for the DNA of HPV. All the samples were tested in duplicate.

\section{4. $n P C R$ for amplification of $H P V$}

For HPV detection, the pairs of primers MY09/11 were used in combination with the pair GP5/6+ of Invitrogen Life Technologies ${ }^{\circledR}$, Brazil, resulting in a fragment of $140 \mathrm{bp}[15,16]$, and they allowed the detection of a series of types of HPV, among them HPV-6, -11, $-16,-18,-31$ e -33 [16]. As positive control for infection by HPV, a sample of HeLa, a lineage uterine cervical carcinoma cells with up to 4 copies of HPV-18 per cell were used. The negative control consisted of a mixture of amplification and ultrapure water. The 
Table 1

Comparative analysis of smokers in both groups.

\begin{tabular}{|c|c|c|c|c|c|c|c|c|c|c|c|}
\hline \multirow[t]{2}{*}{ Group } & \multirow[t]{2}{*}{ Tobacco } & \multirow[t]{2}{*}{ Total (n) } & \multicolumn{2}{|l|}{ Tissue } & \multirow[t]{2}{*}{$p$} & \multicolumn{2}{|l|}{ Plasma } & \multirow[t]{2}{*}{$p$} & \multicolumn{2}{|l|}{ Saliva } & \multirow[t]{2}{*}{$p$} \\
\hline & & & HPV + & HPV - & & $\mathrm{HPV}+$ & HPV - & & HPV + & HPV - & \\
\hline Leukoplakia & Smokers & 29 & 19 & 10 & 0.617 & 14 & 15 & 0.209 & 18 & 11 & 0.510 \\
\hline Control & Smokers & 13 & 7 & 6 & & 6 & 7 & & 5 & 8 & \\
\hline Leukoplakia & Non-smokers & 3 & 3 & 0 & a & 1 & 2 & a & 2 & 1 & a \\
\hline Control & Non-smokers & 11 & 4 & 7 & & 7 & 4 & & 7 & 4 & \\
\hline
\end{tabular}

Fisher's exact test.

a Could not perform the test.

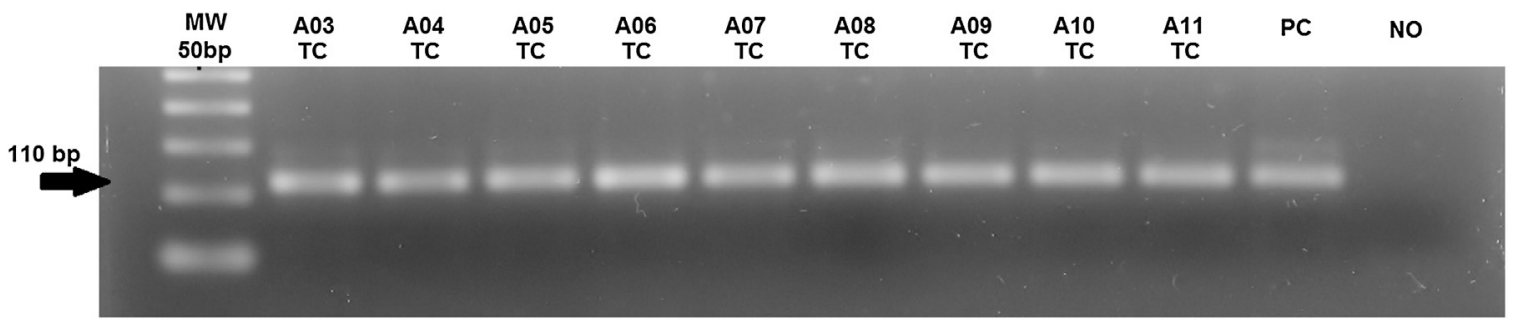

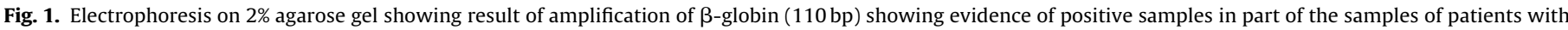
oral leukoplakia (Group A).

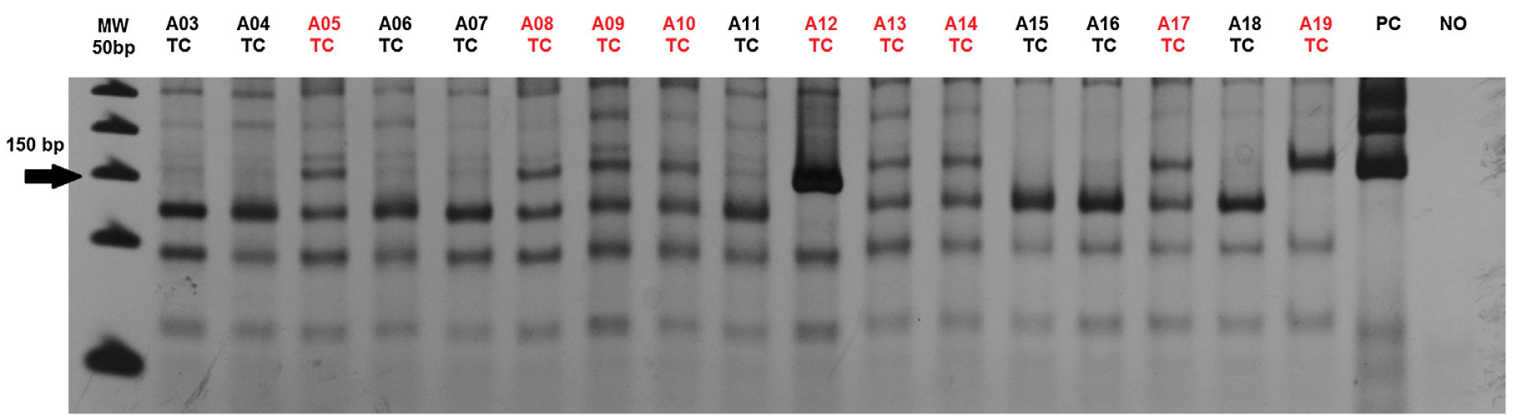

Fig. 2. Electrophoresis on $8 \%$ agarose gel showing result of amplification of HPV (140 bp) by nPCR in part of the samples of patients with oral leukoplakia (Group A).

nPCR products were submitted to electrophoresis in $8 \%$ polyacrylamide gel and the bands were revealed in a silver nitrate solution (Fig. 2). This process was repeated for each sample (saliva, plasma and tissue). All the samples were tested in duplicate.

\subsection{Data analysis}

The Chi-square and Exact Fisher tests were applied for comparison between the study and control groups for each type of material and comparison of the results between the different sources of materials. Logistic regression was performed for analysis of the following variables: sex, age, location of lesion, tobacco, alcohol, presence and absence of HPV. Odds ratios (ORs) and their 95\% confidence intervals $(\mathrm{CI})$ were calculated for comparison among the three human material sources and smoking. The proportion test was applied to evaluate the coincidence of positive samples in epithelial tissue with those positive in saliva in the study and control groups. All the analyses were performed using the statistical software program SAS (Statistical Analysis System), version 9.1. The level of significance adopted was $5 \%$.

\section{Results}

A total of 32 patients with oral leukoplakia and 28 control patients were selected. Four patients in the control group were excluded from the study, because it was not possible to pair them with the study group as regards sex or age. The mean age of Study
Group patients was 56.6 years (25-74; standard deviation 11 ; standard error 1.9) and male:female ratio was 2.1:1. In the control group, the mean age was 56.5 years (26-69; standard deviation 10.7; standard error 1.9) and male:female ratio was 1.4:1.

The area most affected by the leukoplakia lesions was the buccal mucosa region (28.13\%) followed by the floor of the mouth (18.75\%), labial mucosa (18.75\%), tongue (15.63\%), alveolar ridge (15.63\%) and hard palate region (3.13\%).

In the Control Group patients, the areas where the tissue fragments were removed were: the buccal mucosa (41.7\%), alveolar ridge (37.5\%), tongue (16.7\%) and labial mucosa (4.2\%).

As regards habits, $90.63 \%$ of the patients with leukoplakia used tobacco and 50\% were alcohol consumers. In the control group, $54.2 \%$ of the patients were smokers and $29.2 \%$ were drinkers. There was no statistically significant difference in the comparison between the smoker and non-smoker patients of the two groups $(p=0.356)$; and in the tissue, plasma and saliva sample comparisons, considering the smoker patients. Comparison among the non-smokers was not possible due to the small size of the sample (Table 1).

The presence of HPV was detected in $68.75 \%$ (22/32) and in $45.8 \%$ $(11 / 24)$ of the fresh tissue samples in the study and control groups, respectively $(p=0.334)$. In the plasma samples, $50 \%(16 / 32)$ of the study group and 54.2\% (13/24) of the control were positive for HPV $(p=0.723)$. With regard to saliva, 62.5\% (20/32) and 50\% (12/24) of the samples of the study and control groups were positive for HPV $(p=0.925)$ (Table 2). 
Table 2

Analysis of the presence and absence of HPV between the groups with and without oral leukoplakia.

\begin{tabular}{|c|c|c|c|c|}
\hline \multicolumn{5}{|c|}{ Analysis case-control } \\
\hline & & $\mathrm{HPV}+(\%)$ & HPV - (\%) & $p$ \\
\hline \multirow[t]{2}{*}{ Tissue } & Case $(\mathrm{N}=32)$ & $22(68.8)$ & $10(31.3)$ & \multirow[t]{2}{*}{$0.3348^{*}$} \\
\hline & Control $(\mathrm{N}=24)$ & $11(45.8)$ & $13(54.2)$ & \\
\hline \multirow[t]{2}{*}{ Plasma } & Case $(\mathrm{N}=32)$ & $16(50.0)$ & $16(50.0)$ & \multirow[t]{2}{*}{$0.7231^{* *}$} \\
\hline & Control $(\mathrm{N}=24)$ & $13(54.2)$ & $11(45.8)$ & \\
\hline \multirow[t]{2}{*}{ Saliva } & Case $(\mathrm{N}=32)$ & $20(62.5)$ & $12(37.5)$ & \multirow[t]{2}{*}{0.9259} \\
\hline & Control $(\mathrm{N}=24)$ & $12(50.0)$ & $12(50.0)$ & \\
\hline
\end{tabular}

${ }^{*}$ = Fisher's exact test.

= Chi-square test.

Table 3

Comparison between the material sources in the samples of the study and control groups.

\begin{tabular}{lll}
\hline Comparison between the materials sources & \\
\hline Variable & Control group & Study group \\
& $P^{*}$ & $P^{*}$ \\
\hline Tissue $\times$ Saliva & 0.8392 & 0.5726 \\
Tissue $\times$ Plasma & 0.0463 & $0.0269^{\dagger}$ \\
Plasma $\times$ Saliva & 0.2078 & 0.4652 \\
\hline
\end{tabular}

* Fisher's exact test.

$\dagger$ Statistically significant.

In the analysis of HPV positivity between the different types of materials, a significant value was found for the variable tissue versus plasma ( $p=0.0269$ ) in the study group (Table 3 ).

When crossing the values between the presence and absence of HPV, among both patients with oral leukoplakia and those of the control group, the following variables were not statistically significant: sex, age, smoking, alcoholism and degree of dysplasia (Tables 4 and 5).

Odds ratios (ORs) and their 95\% confidence intervals (CI) can be observed in Table 6. Smoking had an intervention of 6 times, and tissue three times, for the diagnosis of leukoplakia or control. Plasma and saliva there were no differences in intervention between the groups (Table 6).

Analysis of the positive samples in tissue that coincided with the positive samples in the other sources, showed statistically signifi- cant difference between the study and control groups in the plasma samples $(p=0.006)$. The other sources presented no statistically significant difference (Table 7).

\section{Discussion}

While the relationship between HPV and oropharyngeal carcinoma is well established, the association of HPV with oral cancer and oral leukoplakia has been controversial [17], with the rate of virus expression between 0 and $100 \%[4,17]$. This variation in the rate may be related with the differences in the types of sample, detection methods or geographic locations used $[17,18]$. Nested PCR, considered to have the highest sensitivity, was the method used in this study for HPV detection, as it is capable of detecting even a single copy of viral DNA per infected cell [18]. This method was the same as that used in various studies $[1,15,19]$, and we believe that this fact did not affect the study results.

There are few studies that detected the presence of HPV in oral leukoplakia in Brazil, thus it was difficult to compare the results. Acay et al. [20] detected the presence of HPV in 24\% of patients with oral leukoplakia and SCC, while Soares et al. [21] found HPV in only $10 \%$ of oral leukoplakia cases. Both studies showed a lower HPV detection rate than observed in our study, probably due to the method used, since both studies used in situ hybridization, considered to have lower sensitivity compared with PCR assay [18,21]. Tristão et al., conducted an epidemiological study in a Brazilian population, with 125 oral mucosa swabs from patients without

Table 4

Correlation between the presence of HPV in the different material sources with the clinical variables and risk factors from the patients with oral leukoplakia.

\begin{tabular}{|c|c|c|c|c|c|c|c|c|c|c|}
\hline \multicolumn{11}{|c|}{ Clinical-pathological variables - Study Group } \\
\hline \multirow[t]{3}{*}{ Demographics/characteristics } & \multirow{3}{*}{$\begin{array}{l}\text { Patients }(\mathrm{n}=32) \\
\mathrm{n}(\%)\end{array}$} & \multirow{2}{*}{\multicolumn{2}{|c|}{$\frac{\text { Tissue }}{\text { HPV }}$}} & \multirow[b]{3}{*}{$P^{*}$} & \multirow{2}{*}{\multicolumn{2}{|c|}{$\begin{array}{l}\text { Plasma } \\
\text { HPV }\end{array}$}} & \multirow[b]{3}{*}{$P^{*}$} & \multicolumn{3}{|c|}{ Saliva } \\
\hline & & & & & & & & \multirow{2}{*}{$\begin{array}{l}\text { HPV } \\
+\end{array}$} & \multirow[b]{2}{*}{-} & \multirow[b]{2}{*}{$P^{*}$} \\
\hline & & + & - & & + & - & & & & \\
\hline \multicolumn{11}{|l|}{ Sex } \\
\hline Male & $21(65.6)$ & 13 & 8 & \multirow[t]{2}{*}{$0.248^{\dagger}$} & 10 & 11 & \multirow[t]{2}{*}{0.709} & 14 & 7 & \multirow[t]{2}{*}{$0.501^{\dagger}$} \\
\hline Female & $11(34.4)$ & 9 & 2 & & 6 & 5 & & 6 & 5 & \\
\hline \multicolumn{11}{|l|}{ Age } \\
\hline$>45$ & $27(84.4)$ & 19 & 8 & \multirow[t]{2}{*}{$0.645^{\dagger}$} & 14 & 13 & \multirow[t]{2}{*}{$0.626^{\dagger}$} & 17 & 10 & \multirow[t]{2}{*}{0.899} \\
\hline$<45$ & $5(15.6)$ & 3 & 2 & & 2 & 3 & & 3 & 2 & \\
\hline \multicolumn{11}{|l|}{ Tabacco } \\
\hline Smokers & $29(91.6)$ & 19 & 10 & \multirow[t]{2}{*}{$0.219^{\dagger}$} & 14 & 15 & \multirow[t]{2}{*}{$0.544^{\dagger}$} & 18 & 11 & \multirow[t]{2}{*}{0.689} \\
\hline Non- smokers & $3(9.4)$ & 3 & 0 & & 2 & 1 & & 2 & 1 & \\
\hline \multicolumn{11}{|l|}{ Alcohol } \\
\hline Alcoholics & $16(50)$ & 5 & 11 & \multirow[t]{2}{*}{$0.647^{\ddagger}$} & 8 & 8 & \multirow[t]{2}{*}{$0.637^{\ddagger}$} & 8 & 8 & \multirow[t]{2}{*}{$0.136^{\ddagger}$} \\
\hline Abstainers & $16(50)$ & 11 & 5 & & 8 & 8 & & 12 & 4 & \\
\hline \multicolumn{11}{|l|}{ Dysplasia } \\
\hline Presence & $6(18.75)$ & 3 & 3 & \multirow[t]{2}{*}{$0.271^{\dagger}$} & 2 & 4 & \multirow[t]{2}{*}{$0.365^{\dagger}$} & 4 & 2 & \multirow[t]{2}{*}{$0.815^{\dagger}$} \\
\hline Absence & $26(81.3)$ & 19 & 7 & & 14 & 12 & & 16 & 10 & \\
\hline
\end{tabular}

\footnotetext{
* p value.

$\dagger$ Chi-square test.

$\ddagger$ Fisher’s exact test.
} 
Table 5

Correlation between the presence of HPV in the different materials sources with clinicopathological variables and risk factors of patients without oral leukoplakia.

\begin{tabular}{|c|c|c|c|c|c|c|c|c|c|c|}
\hline \multicolumn{11}{|c|}{ Clinical-pathological variables - Control group } \\
\hline \multirow[t]{3}{*}{ Demographic/characteristics } & \multirow{3}{*}{$\begin{array}{l}\text { Patients }(\mathrm{n}=24) \\
\mathrm{n}(\%)\end{array}$} & \multirow{2}{*}{\multicolumn{2}{|c|}{$\begin{array}{l}\text { Tissue } \\
\text { HPV }\end{array}$}} & \multirow[b]{3}{*}{$p^{*}$} & \multirow{2}{*}{\multicolumn{2}{|c|}{$\frac{\text { Plasma }}{\mathrm{HPV}}$}} & \multirow[b]{3}{*}{$p^{*}$} & \multirow{3}{*}{$\begin{array}{l}\text { Saliva } \\
\text { HPV } \\
+\end{array}$} & \multirow[b]{3}{*}{-} & \multirow[b]{3}{*}{$p^{*}$} \\
\hline & & & & & & & & & & \\
\hline & & + & - & & + & - & & & & \\
\hline \multicolumn{11}{|l|}{ Sex } \\
\hline Male & $14(58.3)$ & 6 & 8 & 0.729 & 7 & 7 & 0.627 & 7 & 7 & 0.659 \\
\hline Female & $10(41.7)$ & 5 & 5 & & 6 & 4 & & 5 & 5 & \\
\hline \multicolumn{11}{|l|}{ Age } \\
\hline$>45$ & $19(79.2)$ & 9 & 10 & 0.768 & 11 & 8 & 0.474 & 9 & 10 & 0.615 \\
\hline$<45$ & $5(20.8)$ & 2 & 3 & & 2 & 3 & & 3 & 2 & \\
\hline \multicolumn{11}{|l|}{ Tabacco } \\
\hline Smokers & $13(54.2)$ & 7 & 6 & 0.391 & 6 & 7 & 0.391 & 5 & 8 & 0.219 \\
\hline Non-smokers & $11(45.8)$ & 4 & 7 & & 7 & 4 & & 7 & 4 & \\
\hline \multicolumn{11}{|l|}{ Alcohol } \\
\hline Alcoholics & $7(29.2)$ & 3 & 4 & 0.851 & 4 & 3 & 0.851 & 3 & 4 & 0.653 \\
\hline Abstainers & $17(70.8)$ & 8 & 9 & & 9 & 8 & & 9 & 8 & \\
\hline
\end{tabular}

* p value - Chi-square test.

Table 6

Odds ratios and confidence intervals calculated for the plasma, saliva and tissue samples, and smoking, between study and control group.

\begin{tabular}{|c|c|c|c|c|c|}
\hline \multirow[b]{2}{*}{ Case-control } & \multirow[b]{2}{*}{ Chi-square } & \multirow[b]{2}{*}{$\mathrm{p}$ value } & \multirow[b]{2}{*}{ OR } & \multicolumn{2}{|c|}{ Confidence interval (95\%) } \\
\hline & & & & Inferior limit & Upper limit \\
\hline Smoking & 83.333 & $0.0039^{*}$ & 6.614 & 16.602 & 263.502 \\
\hline Plasma & 0.5675 & 0.4513 & 0.6842 & 0.2545 & 18.393 \\
\hline Saliva & 30.655 & 0.0799 & 24.359 & 0.8917 & 66.543 \\
\hline Tissue & 51.074 & $0.0238^{*}$ & 32.154 & 11.504 & 89.872 \\
\hline
\end{tabular}

* Statistically significant.

Table 7

Analysis of HPV positive tissue samples which coincided with the other sources.

\begin{tabular}{|c|c|c|c|c|c|}
\hline \multicolumn{6}{|c|}{ Proportion Test } \\
\hline & & Number of positive sample & Number of positive samples coincidente in tissue sample & Proportion & $P^{\dagger}$ \\
\hline \multirow[t]{2}{*}{ PLASMA } & Case & 16 & 14 & 87.5 & 0.006 \\
\hline & Control & 13 & 4 & 30.8 & \\
\hline \multirow[t]{2}{*}{ SALIVA } & Case & 20 & 14 & 70 & 0.227 \\
\hline & Control & 12 & 5 & 41.7 & \\
\hline
\end{tabular}

\footnotetext{
${ }^{*}$ Statistically significant.

† $\mathrm{p}$ value.
}

clinical-pathological manifestation associated with the HPV, and they detected the HPV DNA in $23.2 \%$ (29/125) of the samples by the PCR method. Using PCR for the L1 HPV region, Betiol et al. [22], also in a Brazilian population, diagnosed the presence of the HPV in $100 \%$ $(8 / 8)$ of the patients with verrucous leukoplakia. The differences in these positivity rates may be explained by the different PCR primer sets used, because in both cited studies the PCR was performed in a single step. Betiol et al. used the primer pair GP5+/GP6+, and Tristão et al. [23], used the general primers MY09/11, which result in fragments of different sizes that may interfere in positivity results. In our study, we used MY09/MY11-GP5+/GP6+ consensus nested polymerase chain reactions (PCR) that has excellent sensitivity, and was the best choice to avoid false negative results [15].

Comparison between the study and control group showed no difference in the rate of positivity of HPV in any of the sources of materials studied, data that differed from the studies of Acay et al. [20] and Szarka et al. [15] in which infection by HPV showed significantly higher values in patients with leukoplakia when compared with the control patients. Our data corroborate those of Cianfriglia et al. [6] and Kristoffersen et al. [24], findings in a similar manner showing that there was no statistical difference between the groups studied, however, the absolute numbers of the rate of infec- tion by HPV in the groups with leukoplakia were higher than those found in the control group. The authors of the present study recommend follow-up of the HPV-positive lesions, because the overall prevalence of HPV in patients with oral leukoplakia was higher in comparison with those with normal oral mucosa, therefore one must not exclude the possibility that HPV may play an important role in the development of oral leukoplakia.

HPV has a special tropism for basal keratinocytes, and the viral genome undergoes episomal replication during the initial phase of infection, with a few copies of viral DNA per host cell present [7]. The episomal form acts as a reservoir of infected cells and is responsible for the latent state of infection [7], however not all contact with HPV may became productive infection; the host's immune system is sometimes capable of keeping the virus in latency, or it may be sufficient to eliminate the virus before it integrates into the host cell genome [25]. Although nPCR is a widely used method, because of its high specificity and sensitivity, it is important to bear in mind that DNA PCR methods do not necessarily identify transcriptionally active HPV [26]. This was a limitation of our study, because we could not know whether the virus, present in HPV positive samples, could stay in a transcriptionally active or inactive form. At present, the HPV mRNA in situ hybridization (ISH) is considered as the gold 
standard for detecting transcriptionally active HPV, however this test is not easily available, requires more technical expertise and has a high cost $[26,27]$. Another method used as marker of transcriptionally active virus is immunohistochemical (IHC) detection of the tumor suppressor p16INK4 [27]. This is an easy and accessible method, but the its main disadvantage is its low specificity, because p16INK4a overexpression could be caused by molecular alterations in the p16INK4a pathway that are not induced by HPV infection [28].

In this study, no statistical difference was found between the presence of HPV and the variables (sex, age, anatomic location of the lesion, tobacco and alcohol consumption, presence/absence of dysplasia), data similar to those of other studies, in which there was no statistical difference for these variables and the presence of HPV in oral leukoplakias $[1,19,24,29]$. In the group of patients with oral leukoplakia the authors believed that age did not interfere in the status of HPV, differently from the group of patients with SCC of the head and neck, in whom a higher incidence of infection by HPV was reported in young patients, mainly due to sexual habits $[19,30]$. The role of tobacco in the evolution of infection by HPV in the oral cavity continues to be controversial; however, the detection of HPV has been reported with greater frequency in nonsmokers or in patients with less exposure to tobacco and/or alcohol [31-33]. Similarly to other studies [6,34] we found no statistically significant difference between the presence of HPV and tobacco. Regarding the presence and absence of dysplasia in patients with oral leukoplakia, there was no significant difference between the presence and absence of HPV, and we are in agreement with Acay et al. [20] and Soares et al. [21] that HPV does not play a role in the progression of malignancy in oral lesions, however the overall prevalence in oral leukoplakias was higher than it was in the control group, suggesting an important association between HPV oral carcinogenesis.

There is no study about the presence of HPV in the plasma of patients with oral leukoplakia, so this is the first study that has analyzed the presence of HPV in blood plasma samples obtained from patients with oral leukoplakia. The present study confirmed infection by HPV in $50 \%$ of the plasma samples, data showing higher values than those of Capone et al. [35] with $17 \%$ of samples positive for HPV in the plasma of patients with carcinoma of the head and neck. Gnanamony et al. [36] and Cao et al. [9] analyzing patients HPV positive in tissues, obtained $56.4 \%$ and $65 \%$ of samples positive for HPV in plasma, data showing lower values than those of this study. When comparing the samples positive in plasma with those positive in the epithelial tissue, significantly higher values were observed in the results of the group with oral leukoplakia, with $87.5 \%$ of the samples coinciding, when compared with $39.8 \%$ of the coinciding samples in the control group. These data are reinforced by the comparison of plasma samples with those of other sources, in which significant values for tissue were presented $(p=0.0269)$, indicating that they are two dependent sources, similar between them. The DNA of the virus present in the plasma and tissue concomitantly is believed to indicate the presence of active virus, arising from infected cells that become detached and attain the blood stream; whereas, their presence only in plasma, with absence of the DNA of the virus in the tissue of the lesion, may mean only a contamination, and not an established infection itself [35]. Another hypothesis would be that the presence of bacterial infection or inflammation facilitates the permanence of the virus in the circulating blood, since the study of Ma et al. [37] showed that bacteria may form a source of permanence of HPV, which may explain the presence of HPV in the plasma, in the absence of active lesions. We believe that the plasma constitutes an important source of detection of HPV, when there are active lesions, thus it could be used as a non-invasive means of monitoring the presence of virus in lesions related to HPV.
The rate of HPV detection in the tissues of oral leukoplakia was $68.75 \%$, data showing higher values than those of Yang et al. [1] and Ostwald et al. [38], who presented $22.8 \%$ and $22.2 \%$ of samples positive for HPV, respectively. Our data also differed from those found by Saghravanian et al. [2], in which all paraffin-embedded biopsies from oral leukoplakia, analyzed by PCR, were negative for HPV. These differences in the rate of detection may be attributed to the type of tissue used, since the paraffin-embedded tissue presents a higher rate of DNA degradation, due to its fixation in formalin, which may make it difficult to detect the virus [7]. However, Kristoffersen et al. [24] presented data similar to those of the present study, with $64 \%$ of the samples positive, using paraffin-embedded material, which leads one to believe that there are other factors involved. Another factor that may justify the differences in the rates of detection of the virus is the size of the fragment and the amplified region. In the present study, specific primers for the region L1 of the virus were used, which amplified a fragment of $140 \mathrm{bp}$ and presented high sensitivity for detection of the virus, and were the same size of the fragment as those used in other studies [1,24].

Adamopoulou et al. [11] analyzing DNA samples from the cervix and saliva found the presence of HPV in $58.6 \%$ of the saliva samples. Kulkarni et al. [10] evaluated two groups: the saliva of patients with and without SCC, thus they found $70.6 \%$ and $60.4 \%$ of the samples positive for the groups with and without SCC, respectively. These data are similar to those of the present study, in which $62.5 \%$ of the saliva samples of patients with oral leukoplakia and $50 \%$ of samples of the controls were positive for the DNA of HPV. The presence of HPV in saliva does not necessarily mean that the virus was integrated into the host cells, because the virus may be in the episomal form, and not integrated into the DNA of the cell [39], a fact observed in the present research in which $75 \%$ of all the samples positive in saliva were also positive in the tissue of the group with oral leukoplakia. On the other hand, in the control group $40.7 \%$ of the samples positive in saliva were also present in the tissue. Considering these results, one possibility was that the virus detected only in saliva was a circulating form of it, and not necessarily an established infection. We agree with Gupta and Gupta [7] that the sensitivity and specificity of HPV detection in saliva are too low, and the role of HPV detection in this source is still uncertain, therefore for an adequate diagnosis it would be necessary to make a comparison of the presence of virus in other media as well, such as viral inclusion in epithelial tissue, analyzed by means of biopsy fragments.

We believe that the presence of HPV in the control group, found in plasma and saliva samples, may be a transitory infection of the virus in the body, and could afterwards be eliminated; considering that in the majority of cases viral inclusion in the epithelial tissue was not coincident with that found in the other sources.

\section{Conclusion}

Based on the present study, we concluded that there was no difference in the rate of detection of HPV in samples of fresh tissue and saliva obtained from patients with or without oral leukoplakia. Fresh tissue, plasma and saliva were shown to be adequate biologic and feasible sources for the detection of HPV. Plasma is also an important source of virus detection, since the positive samples in this source presented statistically significant correlation $(p=0.006)$ with the samples positive in fresh tissue.

\section{Conflict of interest}

On behalf of all authors, the corresponding author states that there is no conflict of interest. 


\section{Acknowledgements}

The authors thank Prof. Dr. Maria Lúcia Marçal Mazza Sundefeld, for performing the statistical analysis of this study. They also thank the São Paulo State Research Support Foundation - FAPESP for funding this study: Grant \#2011/17791-5, and Grant \#2011/05499-8, São Paulo Research Foundation (FAPESP).

\section{References}

[1] S.W. Yang, Y.S. Lee, T.A. Chen, C.J. Wu, C.N. Tsai, Human papillomavirus in oral leukoplakia is no prognostic indicator of malignant transformation, Cancer Epidemiol. 33 (2) (2009) 118-122, http://dx.doi.org/10.1016/j.canep.2009.05. 003.

[2] N. Saghravanian, N. Ghazi, Z. Meshkat, N. Mohtasham, Human papillomavirus in oral leukoplakia, verrucous carcinoma, squamous cell carcinoma, and normal mucous membrane, Oman Med. J. 30 (6) (2015) 455-460, http://dx. doi.org/10.5001/omj.2015.89.

[3] C. Scheifele, P.A. Reichart, Is there a natural limit of the transformation rate of oral leukoplakia? Oral Oncol. 39 (5) (2003) 470-475.

[4] D. Dalla Torre, D. Burtscher, M. Edlinger, et al., Comparison of the prevalence of human papilloma virus infection in histopathologically confirmed premalignant oral lesions and healthy oral mucosa by brush smear detection, Oral Surg. Oral Med. Oral Pathol. Oral Radiol. 119 (3) (2015) 333-339, http:// dx.doi.org/10.1016/j.00oo.2014.11.013.

[5] V.E. Furrer, M.B. Benitez, M. Furnes, H.E. Lanfranchi, N.M. Modesti, Biopsy vs, superficial scraping: detection of human papillomavirus 6, 11, 16, and 18 in potentially malignant and malignant oral lesions, J. Oral Pathol. Med. 35 (6) (2006) 338-344

[6] F. Cianfriglia, D.A. Di Gregorio, C. Cianfriglia, F. Marandino, R. Perrone Donnorso, A. Vocaturo, Incidence of human papillomavirus infection in oral leukoplakia. Indications for a viral aetiology, J. Exp. Clin. Cancer Res. 25 (1) (2006) 21-28

[7] S. Gupta, S. Gupta, Role of human papillomavirus in oral squamous cell carcinoma and oral potentially malignant disorders: a review of the literature, Indian J. Dent. 6 (2) (2015) 91-98.

[8] A.C. Chen, A. Keleher, M.A. Kedda, A.B. Spurdle, N.A. McMillan, A. Antonsson, Human papillomavirus DNA detected in peripheral blood samples from healthy Australian male blood donors, J. Med. Virol. 81 (10) (2009) 1792-1796, http://dx.doi.org/10.4103/0975-962X.155877.

[9] H. Cao, A. Banh, S. Kwok, et al., Quantitation of human papillomavirus DNA in plasma of oropharyngeal carcinoma patients, Int. J. Radiat. Oncol. Biol. Phys. 82 (3) (2012) 351-358, http://dx.doi.org/10.1016/j.ijrobp.2011.05.061.

[10] S.S. Kulkarni, S.S. Kulkarni, P.P. Vastrad, et al., Prevalence and distribution of high risk human papillomavirus (HPV) types 16 and 18 in carcinoma of cervix saliva of patients with oral squamous cell carcinoma and in the general population in Karnataka, India, Asian Pac. J. Cancer Prev. 12 (3) (2011) 645-648.

[11] M. Adamopoulou, E. Vairaktaris, E. Nkenke, et al., Prevalence of human papillomavirus in saliva and cervix of sexually active women, Gynecol. Oncol. 129 (2) (2013) 395-400, http://dx.doi.org/10.1016/j.ygyno.2013.02.015.

[12] M. SahebJamee, M. Boorghani, S.R. Ghaffari, F. AtarbashiMoghadam, A. Keyhani, Human papillomavirus in saliva of patients with oral squamous cell carcinoma, Med. Oral Patol. Oral Cir. Bucal 14 (10) (2009) e525-e528.

[13] M. Sayyah-Melli, M. Kazemi-Sheshvan, M. Bonyadi, Detection of human papillomavirus in the saliva of women with concurrent human papillomavirus related genital lesions, Saudi Med. J. 32 (2) (2011) 141-146.

[14] C.B. Antoneli, K.B. Ribeiro, S.T. Sredni, et al., Low prevalence of HPV in Brazilian children with retinoblastoma, J. Med. Virol. 83 (1) (2011) 115-118, http://dx.doi.org/10.1002/jmv.21925.

[15] K. Szarka, I. Tar, E. Fehér, et al., Progressive increase of human papillomavirus carriage rates in potentially malignant and malignant oral disorders with increasing malignant potential, Oral Microbiol. Immunol. 24 (4) (2009) 314-318, http://dx.doi.org/10.1111/j.1399-302X.2009.00516.x.

[16] A.M. de Roda Husman, J.M. Walboomers, A.J. van den Brule, C.J. Meijer, P.J. Snijders, The use of general primers GP5 and GP6 elongated at their 3' ends with adjacent highly conserved sequences improves human papillomavirus detection by PCR, J. Gen. Virol. 76 (1995) 1057-1062.

[17] X.J. Chen, K. Sun, W.W. Jiang, Absence of high-risk HPV 16 and 18 in Chinese patients with oral squamous cell carcinoma and oral potentially malignant disorders, Virol. J. 13 (81) (2016), http://dx.doi.org/10.1186/s12985-0160526-2.
[18] S.R. Prabhu, D.F. Wilson, Human papillomavirus and oral disease-emerging evidence: a review, Aust. Dent. J. 58 (1) (2013) 2-10, http://dx.doi.org/10. 1111 /adj.12020.

[19] A.K. Chaturvedi, Epidemiology and clinical aspects of HPV in head and neck cancers, Head Neck Pathol. 6 (Suppl. 1) (2012) S16-S24, http://dx.doi.org/10 1007/s12105-012-0377-0.

[20] R. Acay, N. Rezende, A. Fontes, A. Aburad, F. Nunes, S. Sousa, Human papillomavirus as a risk factor in oral carcinogenesis: a study using in situ hybridization with signal amplification, Oral Microbiol. Immunol. 23 (4) (2008) 271-274, http://dx.doi.org/10.1111/j.1399-302x.2007.00422.x.

[21] C.P. Soares, I. Malavazi, R.I. dos Reis, Presence of human papillomavirus in malignant oral lesions, Rev. Soc. Bras. Med. Trop. 35 (5) (2002) 439-444.

[22] J.C. Betiol, S. Kignel, W. Tristão, A.C. Arruda, S.K. Santos, R. Barbieri, J. de Sousa Ribeiro Bettini, HPV 18 prevalence in oral mucosa diagnosed with verrucous leukoplakia: cytological and molecular analysis, J. Clin. Pathol. 65 (8) (2012) 769-770, http://dx.doi.org/10.1136/jclinpath-2012-200673.

[23] W. Tristão, R.M. Ribeiro, C.A. Oliveira, J.C. Betiol, J. de Sousa, R. Bettini, Epidemiological study of HPV in oral mucosa through PCR, Braz. J. Otorhinolaryngol. 78 (4) (2012) 66-70.

[24] A.K. Kristoffersen, M. Enersen, E. Kverndokk, et al., Human papillomavirus subtypes in oral lesions compared to healthy oral mucosa, J. Clin. Virol. 53 (4) (2012) 364-366, http://dx.doi.org/10.1016/j.jcv.2011.12.023.

[25] J. Doorbar, Latent papillomavirus infections and their regulation, Curr. Opin. Virol. 3 (4) (2013) 416-421, http://dx.doi.org/10.1016/j.coviro.2013.06.003.

[26] A. Mahajan, Practical issues in the application of p16 immunohistochemistry in diagnostic pathology, Hum. Pathol. 51 (2016) 64-74, http://dx.doi.org/10. 1016/j.humpath.2015.12.021.

[27] D. Brauswetter, E. Birtalan, K. Danos, A. Kocsis, T. Krenacs, J. Timar, R. Mihalyi, D. Horcsik, G. Polony, L. Tamas, I. Petak, p16INK4 expression is of prognostic and predictive value in oropharyngeal cancers independent of human papillomavirus status: a Hungarian study, Eur. Arch. Otorhinolaryngol. (2016), http://dx.doi.org/10.1007/s00405-016-4412-8.

[28] S.H. Michaelsen, C.G. Larsen, C. von Buchwald, Human papillomavirus shows highly variable prevalence in esophageal squamous cell carcinoma and no significant correlation to p16INK4a overexpression: a systematic review, J. Thorac. Oncol. 9 (6) (2014) 865-871, http://dx.doi.org/10.1097/JTO. 0000000000000166.

[29] G. Campisi, L. Giovannelli, P. Ammatuna, Proliferative verrucous vs conventional leukoplakia: no significantly increased risk of HPV infection, Oral Oncol. 40 (8) (2004) 835-840.

[30] G. Pannone, A. Santoro, S. Papagerakis, L. Lo Muzio, G. De Rosa, P. Bufo, The role of human papillomavirus in the pathogenesis of head \& neck squamous cell carcinoma: an overview, Infect. Agent Cancer 6 (2011) 4, http://dx.doi. org/10.1186/1750-9378-6-4.

[31] E.M. Smith, J.M. Ritchie, K.F. Summersgill, Age, sexual behavior and human papillomavirus infection in oral cavity and oropharyngeal cancers, Int. J. Cancer 108 (5) (2004) 766-772.

[32] D. Esquenazi, I. Bussoloti Filho, G. Carvalho Mda, F.S. Barros, The frequency of human papillomavirus findings in normal oral mucosa of healthy people by PCR, Braz. J. Otorhinolaryngol. 76 (1) (2010) 78-84.

[33] L. Feller, J. Lemmer, Oral leukoplakia as it relates to HPV infection: a review, Int. J. Dent. 2012 (2012) 540561, http://dx.doi.org/10.1155/2012/540561.

[34] M. Bouda, V.G. Gorgoulis, N.G. Kastrinakis, High risk HPV types are frequently detected in potentially malignant and malignant oral lesions, but not in normal oral mucosa, Mod. Pathol. 13 (6) (2000) 644-653.

[35] R.B. Capone, S.I. Pai, W.M. Koch, et al., Detection and quantitation of human papillomavirus (HPV) DNA in the sera of patients with HPV-associated head and neck squamous cell carcinoma, Clin. Cancer Res. 6 (11) (2000) 4171-4175.

[36] M. Gnanamony, A. Peedicayil, J. Subhashini, et al., Detection and quantitation of HPV 16 and 18 in plasma of Indian women with cervical cancer, Gynecol. Oncol. 116 (3) (2010) 447-451, http://dx.doi.org/10.1016/j.ygyno.2009.10. 081.

[37] Z. Ma, L. Liu, F. Zhang, Human papillomavirus type 16 exists in bacteria isolated from cervical cancer biopsies, J. Int. Med. Res. 37 (4) (2009) 1065-1074.

[38] C. Ostwald, K. Rutsatz, J. Schweder, W. Schmidt, K. Gundlach, M. Barten, Human papillomavirus 6/11, 16 and 18 in oral carcinomas and benign oral lesions, Med. Microbiol. Immunol. 192 (3) (2003) 145-148.

[39] M.W. Lingen, Can saliva-based HPV tests establish cancer risk and guide patient management? Oral Surg. Oral Med. Oral Pathol. Oral Radiol. Endod. 110 (3) (2010) 273-274, http://dx.doi.org/10.1016/j.tripleo.2010.06.002. 